\title{
The Efficacy of Systemic Corticosteroids in Treatment of Respiratory Tract Infections During Hajj 2012
}

\author{
Aminreza Tabatabaei ${ }^{1}$; Abbas Heidarzadeh ${ }^{2}$; Navvab Shamspour ${ }^{1, *}$; Pirhosein Kolivand ${ }^{3}$ \\ ${ }^{1}$ Department of Education and Research, Hajj and Pilgrimage Medical Center, Tehran, IR Iran \\ 2 Department of Pharmacutical, Hajj and Pilgrimage Medical Center, Tehran, IR Iran \\ ${ }^{3}$ Clinical Research Center, Khatam-ol-Anbia Hospital, Tehran, IR Iran \\ ${ }^{*}$ Corresponding Author: Navvab Shamspour, Department of Education and Research, Hajj and Pilgrimage Medical Center, Tehran, IR Iran. Tel: +98-2186744114, Fax: +98-2188912476, \\ E-mail:art@hmc.ir
}

Received: June 11, 2013; Revised: January 28, 2014; Accepted: November 1, 2014

\begin{abstract}
Background:Diagnosis and treatment of respiratory tract infections(RTI)in a mass-gathering situation such as hajj is a medical challenge that requires quick decision-making and considerable knowledge about its etiology and treatment methods. High prevalence of RTI during Hajj and tendency of caravan physicians to treat of patients quickly in such situation lead to prescription of parenteral steroids. Nonetheless, no study has focused on the short-term and long-term effects of systemic steroids in Hajj pilgrims with RTI.

Objectives: This study focuses on efficacy of systemic consumption of corticosteroids in alleviating symptoms of RTI.

Patients and Methods: This clinical trial was included 1671 pilgrims in Hajj 2012 who had symptoms of RTI based on caravan physician's findings. The patients were divided to two groups to receive either parenteral corticosteroid or other drugs. Patients who received antibiotics for bacterial infections were excluded. This survey concentrated on general symptoms of RTI during Hajj such as fever, musculoskeletal pain, coryza, sore throat, cough, dyspnea, and hoarseness before, 24 hours after, and five days after drug consumption. For classification and analysis of data, SPSS 17 was used. Descriptive statistical and Chi square test were used to compare variables.

Results: In comparison to corticosteroid injection, treatment without systemic corticosteroids could reduce the fever more significantly within five days $(\mathrm{P}<0.05)$, while it had no effect after 48 hours $(\mathrm{P}>0.05)$. Although corticosteroids alleviated the symptoms during the first 48 hours $(\mathrm{P}>0.05)$, they had no more effect after five days of consumption $(\mathrm{P}>0.05)$. Treatment with medications other than corticosteroid had less effect on reducing coryza $(\mathrm{P}>0.05)$ while corticosteroids had significant alleviating effect on coryza, cough, and musculoskeletal pain $(\mathrm{P}<0.05)$.

Conclusions: There is a need to conduct more comprehensive studies on effect of combination therapy with corticosteroids and antibiotics as well as their short-term and long-term adverse effects on the immune system. While injecting corticosteroids is commonly administered in patients with RTI, they are not recommended due to the lack of data on their long-term therapeutic and adverse effects.
\end{abstract}

Keywords:Corticosteroids; Fever; Hoarseness; Cough

\section{Background}

Each year, over two million pilgrims from all over the world gather in Mecca to perform the Hajj Rites. Such congregation is expected to facilitate transmission of pathogenic organisms, especially viruses that lead to respiratory tract infections (RTI) (1). RTI is a common illness and the most common cause of the hospital admissions during Hajj in Mecca and Medina (2). The Common Cold is the most prevalent type of contracted RTI during the Hajj. Other viral infections such as influenza might lead to severe diseases among pilgrims since many of pilgrims are the elderly. Crowded places, fatigue, and the extreme climatic conditions are important factors for transmitting air-borne and droplet-borne infections (2). This imposes considerable burden by increasing healthcare costs, hospital-bed demand, and lost workdays, and might disseminate infection across continent (3). Choosing the best treatment strategy would help reduce costs and take advantage of this spiritual opportunity. System- ic corticosteroids have been demonstrated to increase the likelihood of resolution or improvement of symptoms in acute sinusitis, viral croup, and sore throats. Corticosteroids are known as of the most effective drugs in treatment of respiratory diseases symptoms $(4,5)$; however, few studied have focused on the short-term and long-term effects of the drug in Hajj pilgrims with RTI.

\section{Objectives}

Considering the importance of physical health during Hajj and the high prevalence of RTI, this study aimed to evaluate the efficacy of corticosteroids on RTI symptoms.

\section{Patients and Methods}

This clinical trial included 180 Iranian pilgrims' caravans during Hajj 2012. These convoys were chosen between 600 Iranian convoys based on population known

Copyright (C) 2015, Iranian Red Crescent Medical Journal. This is an open-access article distributed under the terms of the Creative Commons Attribution-NonCommercial 4.0 International License (http://creativecommons.org/licenses/by-nc/4.0/) which permits copy and redistribute the material just in noncommercial usages, provided the original work is properly cited. 
Tabatabaei A et al.

Table 1. Effect of Systemic Corticosteroids on Fever, Musculoskeletal Pain, Coryza, Sore Throat, Cough, and Hoarseness in Respiratory Tract Infections ${ }^{\text {a }}$

\begin{tabular}{lccc}
\hline Clinical Symptoms & Before Treatment & 24 Hours After Treatment & 48 Hours After Treatment \\
\hline Fever & 49.76 & $12.8^{\mathrm{b}}$ & 54.2 \\
\hline Musculoskeletal pain & 70 & $8.2^{\mathrm{b}}$ & $6.1^{\mathrm{b}}$ \\
\hline Coryza & 74.5 & $20.1^{\mathrm{b}}$ & $14.3^{\mathrm{b}}$ \\
\hline Sore throat & 89.3 & $33.6^{\mathrm{b}}$ & $73.1^{\mathrm{b}}$ \\
Hoarseness & 75.2 & $29.6^{\mathrm{b}}$ & $19.8^{\mathrm{b}}$ \\
\hline Dyspnea & 54 & 55.1 & $26.1^{\mathrm{b}}$ \\
Cough & 89.5 & $33.6^{\mathrm{b}}$ & $26.1^{\mathrm{b}}$ \\
\hline
\end{tabular}

a Data are presented as \%.

${ }^{\mathrm{P}}<0.05$ in comparison with rates before treatment $(95 \% \mathrm{CI})$.

as the Cochran formula. All patients had RTI symptoms based on findings by caravan's physician during Hajj 2012. Any patient with a history of asthma or other lung disease and those who were taking corticosteroids or antibiotics for bacterial infections was excluded. Written informed consent was obtained from all patients.

This study conforms to the international ethic codes and was approved by local ethic committee.. This study concentrated on the effect of corticosteroids on fever, musculoskeletal pain, coryza, sore throat, cough, and hoarseness. The patients were divided into two groups: one group received the parenteral corticosteroid and other group received drugs other than corticosteroid or conservative measures. A double-blinded study was not possible because it was done during Hajj season. Caravans' physicians in 180 convey were obliged to follow patients who were on corticosteroids. In 50 conveys, patients who had received non-corticosteroid treatment were followed. All of the patients with RTI were included in this study. This study concentrated on general symptoms of RTI during Hajj such as fever, musculoskeletal pain, coryza, sore throat, cough, dyspnea, and hoarseness before, 24 hours after, and five days after drug consumption. Patients were screened for eligibility when physicians were available in each caravan. The data was collected in three phases: before, 24 hours after, and five days after drug consumption. In this study, no intervention was performed by physician and data on diagnosis and treatment were extracted from a checklist by medi$\mathrm{cal}$ researcher. Collected data were delivered into a computer and analyzed by SPSS 17 (SPSS Inc., Chicago, IL, USA). Chi square test were used to compare variables. The alpha level was set at 0.05 for all analyses and 95\% confidence intervals were calculated.

\section{Results}

A total of 1670 patients were screened in this study with 785 (47\%) being women. The mean age of these patients was $54.13 \pm 20.05$ years (range, 15-92). Overall, 1321 patients (79.1\%) had upper RTI and 207 (12.34\%) had lower RTI with both upper and lower RTI in 143 patients (8.56\%). In ad- dition, 1076 patients (64.4\%) received parenteral corticosteroids among which dexamethasone was administered to 1398 (83.7\%), betamethasone to $97(5.8 \%)$, L-betamethasone to $44(2.6 \%)$, hydrocortisone to seven patients $(0.4 \%)$ while eight patients (7.5\%) had received drugs other than corticosteroids. Among all prescribed drugs, betamethasone and dexamethasone could lower the fever from $56 \%$ to $9.6 \%$ within the first 24 hours after the consumption. Table 1 shows a significant reduction of fever. The coryza, musculoskeletal pain, hoarseness, cough, and sore throat were relieved significantly within 24 hours and five days of treatment. In comparison to corticosteroids, non-corticosteroid regimens could significantly reduce the fever after five days of treatment; however, they had no effect after 48 hours whereas corticosteroids treated the symptoms in 48 hours but they had no long-term effect after five days of consumption. Additionally, non-corticosteroid drugs had no effect on coryza while corticosteroids had significant effect on coryza, cough, and musculoskeletal pain. In comparison to corticosteroid injection, the treatment without using systemic corticosteroids could reduce the fever more significantly within five days of treatment $(P<0.05)$, while it had no effect after 48 hours $(P>0.05)$. Although corticosteroids alleviated the symptoms in the first 48 hours $(\mathrm{P}>0.05)$, they had no additional effect after five days of consumption $(\mathrm{P}>0.05)$. Non-corticosteroid treatment had less effect on coryza ( $P$ $>0.05$ ) while corticosteroids had significant effect on relief of coryza, cough, and musculoskeletal pain $(\mathrm{P}<0.05)$.

\section{Discussion}

It seems that non-corticosteroid treatments have significant effect on reduction of fever and they indicated better results in long-term consumption in comparison with systemic corticosteroids. This study showed that parenteral corticosteroid drugs would significantly alleviate coryza, musculoskeletal pain, hoarseness, cough, and sore throat. This study was the first study that evaluated the influence of corticosteroid treatments on symptoms of RTI during Hajj and these results can help to design treatment protocols for RTI in Hajj. Previ- 
ous studies assessing the benefits and adverse effects of corticosteroids in treating acute sore throat suggested a more quick alleviation of throat discomfort with corticosteroid administration that lasted for only 24 to 48 hours. Moreover, a recent systematic review on this issue concluded that in addition to antibiotic use, corticosteroids provide symptomatic relief of pain in sore throat. This conclusion was made based on a six-hour decrease in the mean interval to onset of pain relief $(6,7)$. Recently, there has been an increased interest in the use of adjunctive anti-inflammatory medication in addition to antibiotic treatment in patients with pneumonia. As discussed above, an ideal anti-inflammatory drug would be able to reduce the excessive systemic complications of the inflammatory response without affecting the necessary response required for resolution of local inflammation. All the above mentioned drugs are able to reduce the inflammatory response (8); however, the inflammatory response differs widely between patients with regard to age, causative microorganism, and comorbidities as well as many other characteristics. Some patients might require a high dose of anti-inflammatory drugs, whereas others would not benefit from this medication at all. Unfortunately, the long-term effects of multiple administrations of corticosteroids (especially in recurrent cases) are rarely considered. Long-term corticosteroid therapy has been linked to decreased bone mineral density (9). In addition, there are many conservative treatments such as rest, fluids, warm salt water gargling, and anesthetic lozenges, which might provide beneficial effects without accompanying risk of adverse events (10). Future research concerning the role of corticosteroids as adjunctive therapy in patients with RTI will have to clarify the current uncertainties. First, the existing results need to be confirmed in a large, multicenter, preferably with patients stratified by severity of pneumonia. This study needs to be sufficiently powered to analyze the beneficial effect of corticosteroids in subclasses of patients, such as those with high cytokine responses or with discrepancies between cortisol levels and cytokine responses. Secondly, as mentioned above, adjunctive treatment with corticosteroids may not be beneficial to all patients (11). Excessive inflammatory response during pneumonia is not experienced by all patients. In patients with an otherwise modest inflammatory response, use of corticosteroids might be unfavorable. A large study is also needed to characterize patients' with unfavorable effects of corticosteroid treatment and to evaluate potential harms owing to corticosteroids. A variety of anti-inflammatory agents might provide benefits in treatment of sore throat through the mitigation of inflammation. Corticosteroids are an appealing, inexpensive, and familiar agent to be used to test this anti-inflammatory hypothesis. Physicians could benefit from an evidence-based analysis of this topic. The objective of this study also described the effectiveness and tolerability of using corticosteroids for pain relief in acute pharyngitis (12). Anyway, more com- prehensive studies on effect of combination therapy with these drugs and antibiotics as well as their short-term and long-term adverse effects on the immune system are needed. Finally, the widespread use of corticosteroid injections in patients with RTI is not recommended due to the lack of data on long-term effects of treatment and adverse effects of such injections.

\section{Acknowledgements}

The authors would like to acknowledge the Hajj and Pilgrimage Medical Center.

\section{Authors' Contributions}

Study concept and design: Aminreza Tabatabaei and Abbas Heidarzadeh. Acquisition of data: Abbas Heidarzadeh and Pirhosein Kolivand. Statistical analysis, interpretation of data, and drafting of the manuscript: Aminreza Tabatabaei. Critical revision of the manuscript for important intellectual content: Abbas Heidarzadeh. Administrative, technical, and material support, and study supervision: Pirhosein Kolivand. Corresponding author: Navvab Shamspour.

\section{Financial Disclosure}

Hajj and Pilgrimage Health Research Center of Hajj and Pilgrimage Medical Center.

\section{Funding/Support}

This study was supported by Iranian Red Crescent Society and by Research Department of Hajj Medical center.

\section{References}

1. Riaz A, Mortazavi M. Prevalence of underlying diseases in Tamattu, Medical Congress in Hajj \& Pilgrimage.Tehran; 2011.

2. Ahmed QA, Arabi YM, Memish ZA. Health risks at the Hajj. Lancet. 2006;367(9515):1008-15.

3. Memish ZA, Venkatesh S, Ahmed QA. Travel epidemiology: the Saudi perspective. Int J Antimicrob Agents. 2003;21(2):96-101.

4. World Health O. Health conditions for travellers to Saudi Arabia pilgrimage to Mecca (Hajj). Wkly Epidemiol Rec. 2005;80(4950):431-2.

5. Pauwels RA, Buist AS, Calverley PM, Jenkins CR, Hurd SS, Gold Scientific Committee. Global strategy for the diagnosis, management, and prevention of chronic obstructive pulmonary disease. NHLBI/WHO Global Initiative for Chronic Obstructive Lung Disease (GOLD) Workshop summary. Am J Respir Crit Care Med. 2001;163(5):1256-76.

6. Zalmanovici Trestioreanu A, Yaphe J. Steroids for acute sinusitis in adults and children. Health. 2013:34.

7. Wing A, Villa-Roel C, Yeh B, Eskin B, Buckingham J, Rowe BH. Effectiveness of corticosteroid treatment in acute pharyngitis: a systematic review of the literature. Acad Emerg Med. 2010; 17(5):476-83.

8. Hayward G, Thompson M, Heneghan C, Perera R, Del Mar C, Glasziou P. Corticosteroids for pain relief in sore throat: systematic review and meta-analysis. BMJ. 2009;339:b2976.

9. Parameswaran K, O'Byrne PM, Sears MR. Inhaled corticosteroids for asthma: common clinical quandaries. $J$ Asthma. 2003;40(2):107-18.

10. Postma DS, Sevette C, Martinat Y, Schlosser N, Aumann J, Kafe 
H. Treatment of asthma by the inhaled corticosteroid ciclesonide given either in the morning or evening. Eur Respir $J$ 2001;17(6):1083-8.

11. Steinberg KP, Hudson LD, Goodman RB, Hough CL, Lanken PN, Hyzy R, et al. Efficacy and safety of corticosteroids for persistent acute respiratory distress syndrome. $N$ Engl J Med.
2006;354(16):1671-84.

12. Meduri GU, Marik PE, Chrousos GP, Pastores SM, Arlt W, Beishuizen A, et al. Steroid treatment in ARDS: a critical appraisal of the ARDS network trial and the recent literature. Intensive Care Med. 2008;34(1):61-9. 